\title{
PSEUDO-PROPORTIONAL POSITION CONTROL OF WATER HYDRAULIC CYLINDER USING ON/OFF VALVES
}

\author{
Matti LINJAMA, Kari T. KOSKINEN and Matti VILENIUS \\ Institute of Hydraulics and Automation \\ Tampere University of Technology \\ P.O.Box 589, FIN-33101 Tampere, Finland \\ (E-mail: matti.linjama@tut.fi)
}

\begin{abstract}
The paper studies the possibility to replace expensive water hydraulic proportional valve with a number of low-cost on/off valves. A position control system of a water hydraulic cylinder is realized with eight two-way solenoid valves and one four-way on/off valve. A pulse code modulation is used to achieve almost proportional control. A position controller based on multi-rate sampling is developed to minimize position error. Experimental results with a high inertial load show smooth movements, $0.2 \mathrm{~mm}$ position accuracy and $200 \mathrm{~mm} / \mathrm{s}$ maximum velocity. The advantages and disadvantages of the on/off valve system are discussed.
\end{abstract}

\section{KEY WORDS}

Water hydraulics, on/off control, pulse code modulation

\section{INTRODUCTION}

New water hydraulics has been studied and developed actively during the last decade. The research has mainly concentrated on pressure levels between 80 and 160 bar using pure tap water as a fluid medium [1]. The lowpressure water hydraulics has also been studied actively during last few years $[2,3,4]$. Pressure level is below 50 bar, which allows the use of rougher tolerances and lowcost materials. The low-pressure water hydraulics is aimed to be an environmentally friendly and low-cost fluid power technology and it can in many cases replace pneumatic systems because it offers higher stiffness and force level as well as better efficiency.
Proportional position or velocity control of water hydraulic actuators is a challenging problem because of poor availability of valves. Some good proportional and servo valves exist $[5,6]$ but they are quite expensive for wider use. High price is partly caused by the small amount of produced valves but also because of special requirements caused by water (wear and corrosion resistance, tight tolerances etc.). So it can be expected that water hydraulic proportional valves will be more expensive than oil hydraulic valves also in the future. The problem is especially severe in the low-pressure water hydraulics where low price level is one important target. Promising results has been achieved by modifying a pneumatic valve to work as a low-pressure water hydraulic proportional valve [7]. However, the valve 
needs further development in order to achieve good control results [8].

On/off valves are an interesting alternative for proportional valves because of lower cost, better reliability and smaller sensitivity for contamination. A standard way to achieve proportional flow with on/off valves is to use fast and continuous switching of valves. The most popular example is Pulse Width Modulation (PWM). However, water hydraulic on/off valves are usually so slow that these methods don't give satisfactory performance. Noise, pressure ripple and valve wear are also problems in these methods. An alternative way is Pulse Code Modulation (PCM) in which several on/off valves are connected in parallel giving stepwise adjustable flow control. If flow capacities of valves are in ratios of 1:2:4:8:16 etc., it is possible to achieve $2^{n}$ flow steps with $n$ valves. Such on/off valve series is called here digital flow control unit. Other commonly used names in the literature are PCM valve or digital valve. Important advantages of PCM method are that good control results can be achieved with rather slow valves and that there is no need for continuous high-frequency switching of valves. Obvious drawback is that more valves are needed. PCM method is an old idea (see e.g. [9]) but quite seldom applied to hydraulic systems. Virvalo [10] used this principle to adjust the velocity of an oil hydraulic cylinder. Laamanen et al. [11] used a digital flow control unit with seven valves to control the rotational velocity of a water hydraulic motor. The results showed that properly tuned PCM control gives better performance than commercial proportional flow control valve. A method to reduce pressure peaks was also presented in this paper. Liu et al. [12] used PCM method for position control of a spraying robot actuator. The selection of suitable valve sizes and sampling time was discussed and rather good control results were achieved. However, the inertial load of the system was low.

This paper applies PCM method to the position control of a highly loaded water hydraulic cylinder. Important extension to previous research is that two digital flow control units are used to control both inflow and outflow of the actuator. It is also shown that position accuracy can be improved remarkably by using a controller with multirate sampling. Experimental results are presented showing good control performance.

\section{STUDIED SYSTEM}

The studied system is shown in Figure 1. It consists of a water hydraulic pump unit, asymmetric cylinder with inertial load, two digital flow control units and four-way valve for changing direction of movement. Digital flow control units are realized with four directly operated solenoid valves. These valves have been studied in detail in [4]. Each valve has an external orifice so that the flow capacities of valves are approximately in ratios of $1: 2: 4: 8$. Orifice sizes are selected such that the maximum velocity of the cylinder is about $200 \mathrm{~mm} / \mathrm{s}$, which is the highest allowed velocity for the cylinder. The four-way valve is a pneumatic spool type valve but it is also suitable for low-pressure water hydraulic usage. Its flow capacity is so high that pressure losses in the valve are negligible. The system is equipped with $220 \mathrm{~mm}$ 'hose accumulators' in order to reduce pressure peaks at cylinder chambers. The selection of hose lengths and optimal damping orifice sizes is discussed in [13].

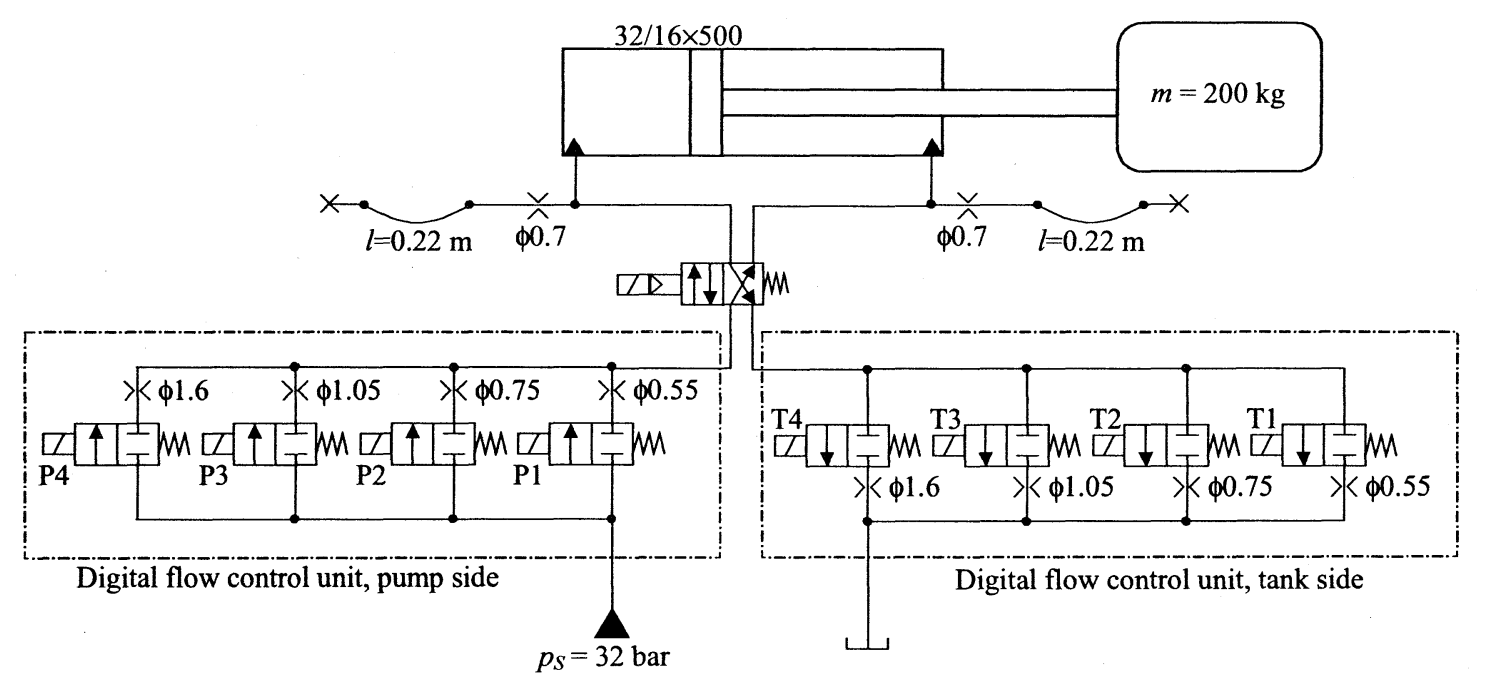

Figure 1. Hydraulic circuit of the studied system. 


\section{CONTROL PRINCIPLES}

The operation principle of the pump side digital flow control unit is shown in Table 1. It is seen that the total number of nonzero flow rates is fifteen. In the ideal case, the step size is constant and equal to the flow rate of the smallest valve. The exact adjustment of valve flow rates is difficult and step sizes are not exactly equal in practice. The operation principle is the same for the tank side digital flow control unit and the system has $15 \times 15=$ 225 different combinations of valve openings giving nonzero cylinder velocity. The whole valve system of Figure 1 is therefore a four-way valve with independently adjustable inflow and outflow. However, this paper concentrates on the simplest case in which equal openings are used in the pump and tank side digital flow control units.

Table 1. Different combinations of valve openings of the digital flow control unit. $0=$ closed valve, $1=$ open valve, $Q=$ flow rate of the smallest valve.

\begin{tabular}{|c|c|c|c|c|c|}
\hline State of unit & P1 & P2 & P3 & P4 & Net flow \\
\hline 0 & 0 & 0 & 0 & 0 & 0 \\
\hline 1 & 1 & 0 & 0 & 0 & $\mathrm{Q}$ \\
\hline 2 & 0 & 1 & 0 & 0 & $2 \times \mathrm{Q}$ \\
\hline 3 & 1 & 1 & 0 & 0 & $3 \times \mathrm{Q}$ \\
\hline 4 & 0 & 0 & 1 & 0 & $4 \times \mathrm{Q}$ \\
\hline 5 & 1 & 0 & 1 & 0 & $5 \times \mathrm{Q}$ \\
\hline 6 & 0 & 1 & 1 & 0 & $6 \times \mathrm{Q}$ \\
\hline 7 & 1 & 1 & 1 & 0 & $7 \times \mathrm{Q}$ \\
\hline 8 & 0 & 0 & 0 & 1 & $8 \times \mathrm{Q}$ \\
\hline 9 & 1 & 0 & 0 & 1 & $9 \times \mathrm{Q}$ \\
\hline 10 & 0 & 1 & 0 & 1 & $10 \times \mathrm{Q}$ \\
\hline 11 & 1 & 1 & 0 & 1 & $11 \times \mathrm{Q}$ \\
\hline 12 & 0 & 0 & 1 & 1 & $12 \times \mathrm{Q}$ \\
\hline 13 & 1 & 0 & 1 & 1 & $13 \times \mathrm{Q}$ \\
\hline 14 & 0 & 1 & 1 & 1 & $14 \times \mathrm{Q}$ \\
\hline 15 & 1 & 1 & 1 & 1 & $15 \times \mathrm{Q}$ \\
\hline
\end{tabular}

The opening and closing delays of valves is one important factor that affects the quality of control. The operation principle of the digital flow control unit calls for simultaneous opening and closing of valves. For example, the change from the state seven to state eight requires simultaneous closing of valves $\mathrm{P} 1, \mathrm{P} 2$ and $\mathrm{P} 3$ as well as opening of $\mathrm{P} 4$, see Table 1 . The flow rate is undetermined during the state change and can be temporarily anything between zero and maximum. This may yield harmful pressure transients especially if the variation in valve operation times is big. The measured opening delay of two-way valves varies between 20 and $33 \mathrm{~ms}$ and closing delay between 5 and $12 \mathrm{~ms}$ [4]. It is therefore important to delay the closing of valves such that valve openings and closings occur as simultaneously as possible. The delay of the four-way valve is $30-40 \mathrm{~ms}$ depending on the direction of spool movement.

The sampling time of the controller has also an important effect on the dynamic response. High performance calls for short sampling time but it cannot be made arbitrarily small because the valves would not have enough time to achieve their states. A reasonable compromise is to select sampling time at least twice the average delay of valve [12].

Two different controllers are studied and the first one is called the simple P-controller. The control principle is to approximate linear flow curve with digital flow control units as well as possible. The state of the digital flow control units as a function of the position error is shown in Figure 2. Higher gain is used in retracting movement to compensate asymmetry of the cylinder. The opening of two-way valves is delayed $18 \mathrm{~ms}$ and the closing is delayed $28 \mathrm{~ms}$. This compensates for difference in opening and closing delays and ensures also that the four-way valve has enough time to achieve correct position before the motion starts. The Simulink realization of the simple $\mathrm{P}$-controller is shown in Figure 3 showing relatively simple structure of the whole control system.

The problem of the simple P-controller is that the operation of two-way valves is delayed always at least $18 \mathrm{~ms}$ degrading the stability of the closed-loop system. The time resolution is also rather poor because of the long sampling time of the controller, which increases position error in the stopping situation.

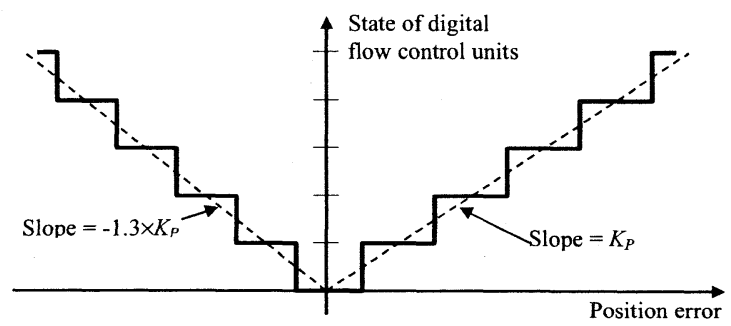

Figure 2. The state of the digital flow control units as a function of position error in the simple P-controller. 


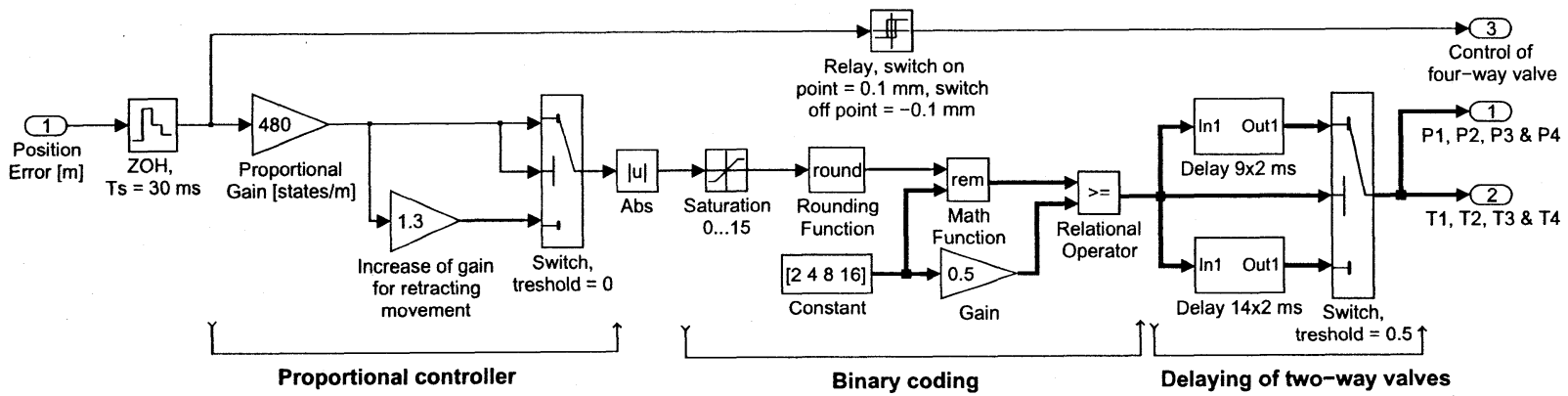

Figure 3. Simulink realization of the simple P-controller.

The basic idea of the improved P-controller is to separate stopping and moving situations. The controller works similarly to the simple P-controller when the position error is large but the opening of two-way valves is not delayed at all and the closing is delayed $10 \mathrm{~ms}$. This can be done because the four-way valve changes its state only when the sign of position error changes. The controller switches to the stopping mode when the position error becomes smaller that the approach distance $x_{a}$. The state of the digital flow control units is one until the position error becomes smaller than the stopping distance $x_{b}$, see Figure 4 . The stopping distance is reduced $50 \mathrm{~ms}$ after closing of valves in order to reduce final position error. Valve closing is not delayed and the sampling time is $2 \mathrm{~ms}$ in the stopping mode, which allows accurate stopping. The delay of the four way valve is considered such that the change of the digital flow control units from state 0 to any nonzero state is delayed $30 \mathrm{~ms}$. This delay has no effect on stability because it occurs only when the motion starts.

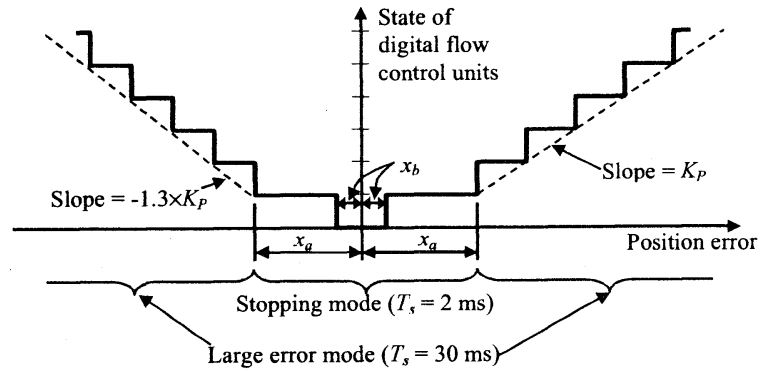

Figure 4. The state of the digital flow control units as a function of position error in the improved P-controller.

\section{EXPERIMENTAL RESULTS}

Both controllers are tested near the middle position of the stroke with $200 \mathrm{~kg}$ load mass. The target position is $250 \mathrm{~mm}$ and the initial position is $180,240,260$ or 320 $\mathrm{mm}$. Each case is repeated twenty times in order to study the effect of variation in valve delays to the response. Controllers are tuned such that there is no overshoot in the response and that the final position error is as small as possible. The controller gain $K_{P}$ is 480 states $/ \mathrm{m}$ for the simple P-controller. According to Figure 2, this means that the position error can vary between $-0.8 \mathrm{~mm}$ and 1.0 $\mathrm{mm}$. The gain can be increased to 600 states $/ \mathrm{m}$ for the improved P-controller because of smaller loop delay. The approach distance $x_{a}$ is selected $1.8 \mathrm{~mm}$ and the stopping distance $x_{b}$ is first $0.4 \mathrm{~mm}$ and is reduced to 0.2 $\mathrm{mm} 50 \mathrm{~ms}$ after the stopping. So the maximum position error is only $0.2 \mathrm{~mm}$ for the improved P-controller.

Figures 5 and 6 show typical step responses with the simple P-controller. Figures 7 and 8 show corresponding responses with the improved $\mathrm{P}$-controller. The position error distributions of all measured responses are presented in Figure 9.
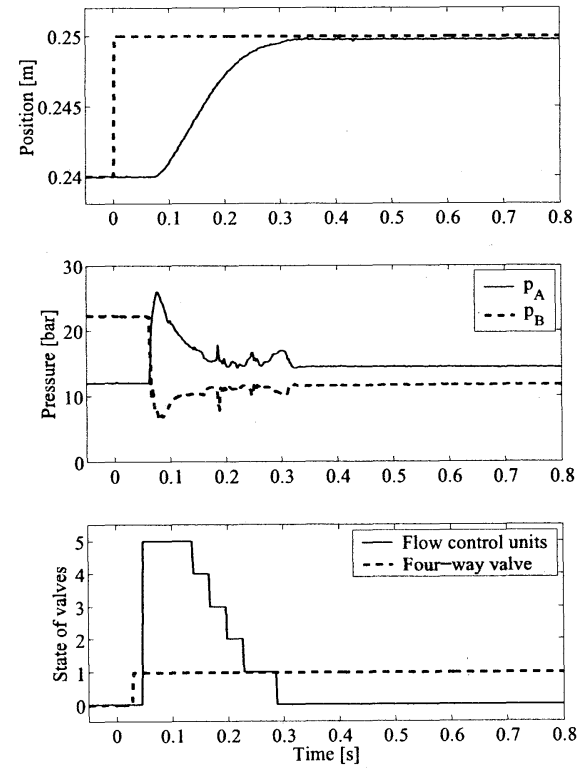

Figure 5. Step response $240->250 \mathrm{~mm}$ with simple P-controller. 

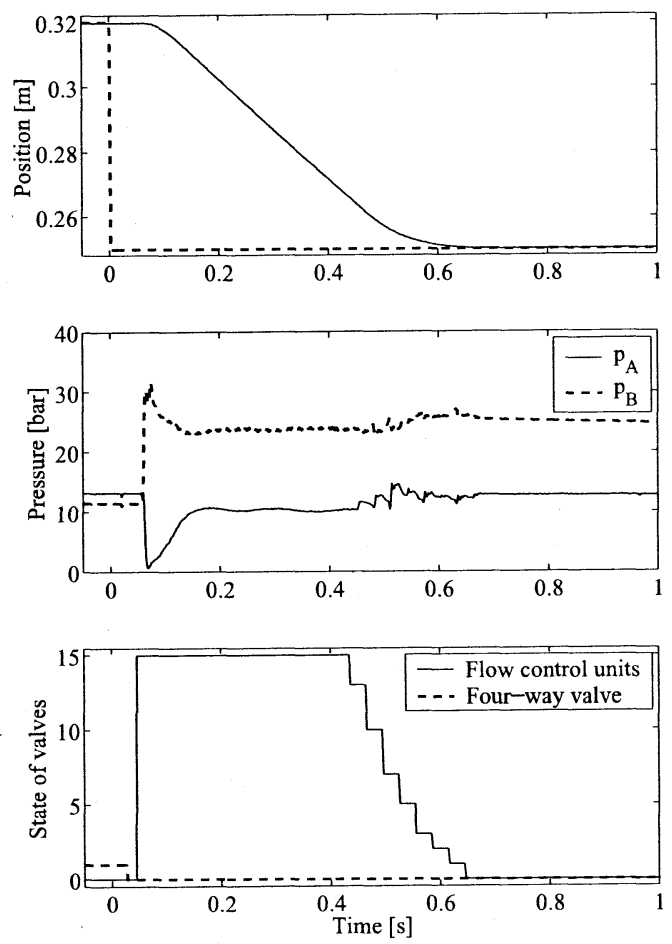

Figure 6. Step response $320->250 \mathrm{~mm}$ with simple P-controller.
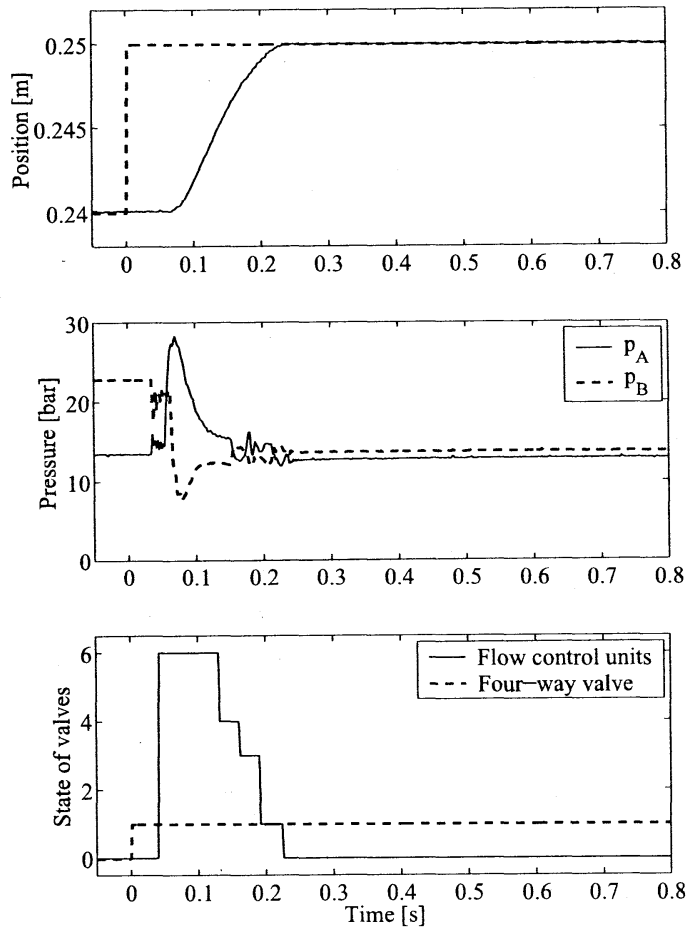

Figure 7. Step response $240->250 \mathrm{~mm}$ with improved P-controller.
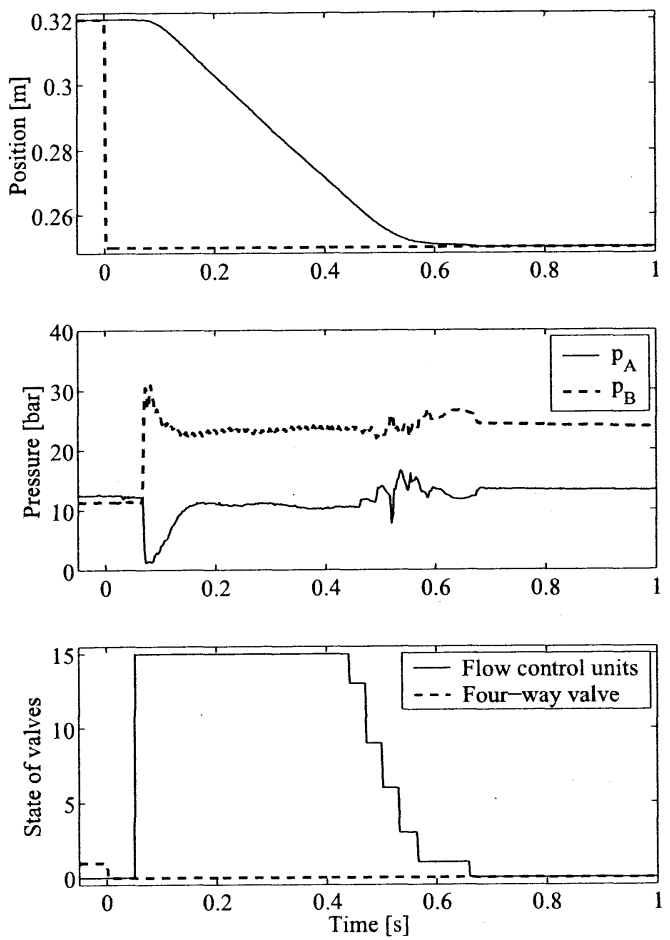

Figure 8. Step response $320->250 \mathrm{~mm}$ with improved P-controller.
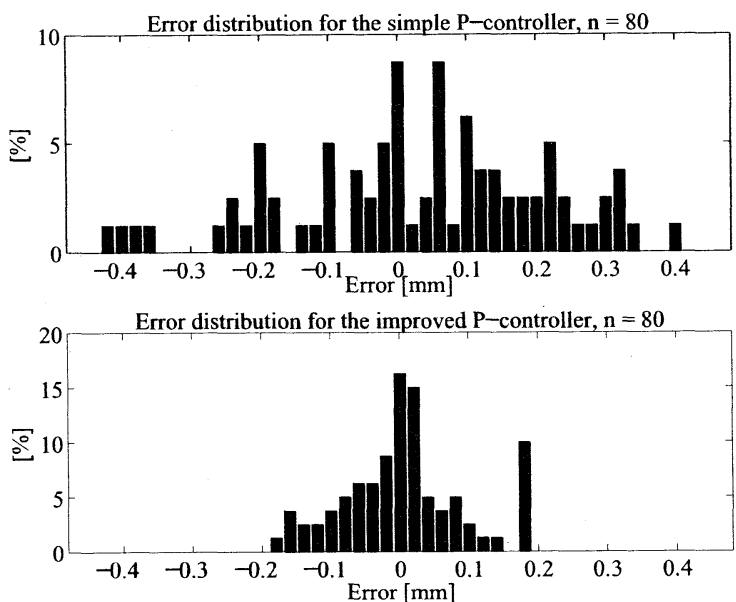

Figure 9. Error distributions of all measured responses.

The improved P-controller was also tested with $100 \mathrm{~kg}$ load mass and different piston positions. The conclusion of these tests is that the middle position is worst operation point and the response slightly improves when the load mass decreases or if the target position is near the cylinder end. Some tests were also made without hose accumulators and rather surprisingly there were no remarkable increase in pressure transients. 


\section{DISCUSSION AND CONCLUSIONS}

The first position control results with the suggested on/off circuit are promising. When compared to the results with the state-of-the-art water hydraulic proportional valve [8], the on/off system gives equally good accuracy and smoothness of motion. The maximum velocity was limited to $200 \mathrm{~mm} / \mathrm{s}$ in this study but adding fifth valve to both digital flow control units would double the velocity without any loss in accuracy.

The presented system gives several benefits when compared to traditional servo systems. On/off valves are simple, low-cost and reliable and there is no need for spool position measurement or sophisticated control electronics. Only a moderate number of valve operations are required for one movement and therefore the valve wear is not a problem. The inflow and outflow of the actuator can be adjusted separately that allows minimization of pressure losses.

The drawbacks of the system are more complex hydraulic circuit, switching noise of valves and increased complexity of the controller. The presented solution doesn't require continuous high frequency switching and the average noise level is much lower than in PWM systems. The comparison between the simple and improved P-controller shows that it is important to consider the on/off nature of valves. This increases complexity of controller and there is also a risk for limit cycles when good accuracy is strived for. Limit cycles were detected in some responses and so the $0.2 \mathrm{~mm}$ accuracy for the improved P-controller is slightly too optimistic. The pressure transients were expected to be a problem but they were small in experimental tests.

To conclude, the results show that good proportional-like motion control of water hydraulic systems is possible with simple and low-cost on/off valves. The further research will concentrate on energy saving possibilities of the system.

\section{ACKNOWLEDGEMENT}

The research was supported by the Academy of Finland (Grant n:o 71635).

\section{REFERENCES}

1. Urata, E. Technological Aspects of the New Water Hydraulics, The Sixth Scandinavian International Conference on Fluid Power, Tampere, Finland, 1999, pp. 21-34.

2. Kunttu, P., Koskinen, K.T. and Vilenius, M. Low Pressure Water Hydraulics - State of the Art, The Sixth Scandinavian International Conference on Fluid Power, Tampere, Finland, 1999, pp. 67-75.
3. Lakkonen, M., Linjama, M., Koskinen, K. and Vilenius, M. Applicability of Pneumatic Cylinders in Low-Pressure Water Hydraulics, Lubricants for Off-Highway Applications, 2000, USA, SAE International, SP-1553, pp. 61-66.

4. Linjama, M., Tammisto, J., Koskinen, K.T. and Vilenius, M. Two-way solenoid valves in lowpressure water hydraulics, In: McLain, T. and Kim, D. (ed.), Fluid Power Systems and Technology 2000 (IMECE2000), ASME, New York, 2000, pp. 55-60.

5. Takahashi, T., Yamashina, C., and Miyakawa, S. Development of Water Hydraulic Proportional Control Valve, The Fourth JHPS International Symposium on Fluid Power, Tokyo, Japan, 1999, pp. 549-554.

6. Hyvönen, M., Koskinen, K.T., Lepistö, J. and Vilenius, M. Experiences of Using Servo Valves with Pure Tap Water, The Fifth Scandinavian International Conference on Fluid Power, Linköping, Sweded, 1997, pp. 21-32 (vol. 2).

7. Sairiala, H., Linjama, M., Koskinen, K.T. and Vilenius, M. Low-Cost Proportional Valve for LowPressure Water Hydraulics. In: Burrows, C.R. and Edge, K.A. (ed.) Bath Workshop on Power Transmission and Motion Control (PTMC2001), Professional Engineering Publishing, London, 2001, pp. 135-145.

8. Sairiala, H., Linjama, M., Koskinen, K.T. and Vilenius, M. Proportional Position Control of LowPressure Water Hydraulic Cylinder. 49th National Conference on Fluid Power, Las Vegas, NV, USA, 2002, pp. 227-234.

9. Bower, J. Digital Fluid Control System, US Patent n:o 2999482, 1961.

10. Virvalo, T. Cylinder Speed Synchronization, Hydraulics \& Pneumatics, Dec 1978, pp. 55-57.

11. Laamanen, A., Linjama, M., Tammisto, J., Koskinen, K.T. and Vilenius, M. Velocity Control of Water Hydraulic Motor, to be published in The Fifth JFPS International Symposium on Fluid Power, Nara, Japan, 2002.

12. Liu, R., Wang, X., Tao, G. and Ding, F. Theoretical and experimental study on hydraulic servo position control system with generalization pulse code modulation control. In: Lu, Y., Ying, C. and $\mathrm{Xu}, \mathrm{L}$. (ed.) Proceedings of the Fifth International Conference on Fluid Power Transmission and Control (ICFP'2001), International Academic Publishers, Beijing, 2001, pp. 176-179.

13. Linjama, M., Koskinen, K.T. and Vilenius, M. Suppression of pressure transients in on/off control of low-pressure water hydraulic cylinder. In: Burrows C.R. and Edge, K.A., (ed.), Bath Workshop on Power Transmission and Motion Control (PTMC2000), Professional Engineering Publishing, London, 2000, pp. 199-212 